ISSN e- 2594-1100

en-claves del pensamiento / núm. 30 / julio-diciembre / 2021 / e408

https://doi.org/10.46530/ecdp.v0i30.408 ARTÍCULOS

\title{
(en-claves
}

\section{MECANISMOS DE CONTROL EN LA VIDA CONVENTUAL FEMENINA EN LA NUEVA ESPAÑA}

Control Mechanisms in Female Conventual Life in New Spain

\author{
María Cristina Ríos Espinosa, Universidad del Claustro de Sor Juana, México \\ Correo electrónico: cristinarios63@hotmail.com
}

Recibido: 30/03/2020

Aceptado: 04/01/2021

Publicado: 01/07/2021

Resumen. En esta investigación se estudiarán los diversos mecanismos de control en la vida de las mujeres de vida conventual en la Nueva España, nos interesa en particular el de la escritura, para ello se revisará un sermón que encontramos dentro del Fondo Conventual de los archivos documentales del Museo Franz Mayer en la Ciudad de México, se titula Avisos espirituales que dio a sus hijas la seráfica doctora Santa Teresa de Jesús, ${ }^{1}$ y explica en pláticas su devoto el ilustrísimo señor Don Joseph Xavier Rodríguez de Arellano (1764-1791), Arzobispo de Burgos, del Consejo de su Majestad y dedica a las venerables preladas y religiosas de los monasterios de su filiación, tomo II, publicado en Burgos en 1780. Del análisis de este sermón, nos interesa la normativa pastoral acerca del uso correcto de la poesía escrita por monjas, para ello, Rodríguez de Arellano emplea dos modelos comparativos de escritura, la de Santa Teresa de Jesús, fundadora de la Orden de las Carmelitas Descalzas en el siglo XVI, con la de sor Juana Inés de la Cruz, monja jerónima novohispana del siglo XVII. Se busca probar las funciones de la escritura y su normativa, establecida por el poder pastoral en tratados espirituales, máximas devocionales y sermones destinados a las monjas, con la finalidad de construir ideales de conducta virtuosa en las religiosas. De igual manera, se analizarán los antecedentes sobre el papel de la escritura de las monjas novohispanas del siglo XVII ordenados por los confesores, para ejercer control y vigilancia en sus vidas dentro de los conventos, formas diversas de tecnologías de interiorización.

Palabras clave: biopolítica-neumática, tecnologías de interiorización, tratados espirituales, vida ascética femenina, escritura conventual.

\footnotetext{
${ }^{1}$ No es un sermón inédito, existen varias copias en Fondos Conventuales Antiguos internacionales, como la Biblioteca Nacional de España (BNE), el Fondo de Archivo del Museo Franz Mayer tiene un tomo original, que fue el que revisamos.
} 
Abstract. This research focuses on the various means of control in the lives of women conventual life in New Spain, particularly the one dealing with writing. To this end, we examine a sermon found in the Conventual Collection of the document archives at the Franz Mayer Museum in Mexico City. In his Avisos espirituales que dio a sus hijas la seráfica doctora Santa Teresa de Jesús [Spiritual advice seraphic doctor St. Teresa of Avila gave to her daughters], ${ }^{2}$ the devout and illustrious Don Joseph Xavier Rodríguez de Arellano of Burgos (1764-1791), Archbishop of Burgos of His Majesty's Council explains through speeches and dedicates the sermon to the venerable prelates and nuns of affiliated monasteries, Volume II, published in Burgos in 1780. In analyzing this sermon, we focus on the pastoral regulations on the correct use of poetry written by nuns, for which Rodríguez de Arellano uses two comparative writing models: that of St Teresa of Avila, the founder of the Order of Discalced Carmelites in the $16^{\text {th }}$ century, and that of Sor Juana Ines de la Cruz, a Novo-Hispanic Hieronymite nun of the $17^{\text {th }}$ century. The aim is to determine the functions of writing and its guidelines established by pastoral authorities in spiritual treatises, devotional maxims and sermons for nuns so as to build ideals of virtuous behavior. Likewise, an analysis is made of the precedents on the role of $17^{\text {th }}$ century Novo-Hispanic nuns' writing as ordered by confessors as a means to exert control and oversight of their lives inside convents, as different forms of interiorized discipline.

Keywords: neuma-biopolitics, technologies of the internal, spiritual treatises, ascetical female life, convent writing.

Cómo citar: Ríos Espinosa, M. (2021). Mecanismos de control en la vida conventual femenina en la Nueva España. EN-CLAVES del pensamiento, O(30), e408. doi: https://doi.org/10.46530/ecdp.v0i30.408

2 This is not an unpublished sermon since there are several copies in international Old Convent endowments, such as the Biblioteca Nacional de España [National Library of Spain] (BNE). The Franz Mayer Museum Archive Collection contains the original volume we viewed. 


\section{Introducción}

El objetivo de la escritura en los monasterios femeninos en la Nueva España fue servir a la práctica devocional y al ejercicio del examen de conciencia de las religiosas, para 1) expresar experiencias místicas; 2) mejorar el "conocimiento de sí"3 mismas, a través de la revisión de faltas, reconocer pensamientos, tentaciones, y deseos distractores de la senda virtuosa, y 3) confesar las propias faltas hacia sí mismas y a un otro, su guía espiritual o confesor. Éstos fueron los modos de reconocimiento de sí mismas o técnicas para el conocimiento de sí mismas, lo que Michel Foucault llamó una "técnica de interiorización”, "hermenéutica del yo" o "técnica del yo". Se busca probar cómo dichas prácticas pueden clasificarse como casos específicos de "biopolítica neumática"4 y "tecnologías del yo", como las entiende este filósofo francés en Tecnologías del yo e Historia de la sexualidad, sólo que a diferencia del objeto de estudio analizado ahí, como fueron las prácticas del cristianismo antiguo y medieval temprano en los monasterios, nosotros nos centraremos en las prácticas de vida ascética conventual femenina, en particular en las funciones de la escritura y su normativa, establecida por el poder pastoral en tratados espirituales, máximas devocionales y sermones destinados a las monjas, no escritos por ellas sino por autoridades eclesiásticas con la finalidad de construir ideales de conducta virtuosa en las religiosas.

\footnotetext{
${ }^{3}$ Este término es analizado por Michel Foucault, en su obra Tecnologías del yo, dentro de su desarrollo de la hermenéutica del yo, en el contexto tanto de la filosofía grecorromana en los dos primeros siglos a. C del bajo imperio romano como en la espiritualidad cristiana, a partir de los principios monásticos que imperaron en los siglos IV y V siglo al final del alto imperio romano. El "conocimiento de sí mismo" o el "conócete a ti mismo" era, según el filósofo "[e]l principio délfico $[\ldots]$ un consejo práctico $[\ldots]$ En los textos griegos o romanos, la exhortación al deber de conocerse a sí mismo estaba siempre asociada con el otro principio de tener que preocuparse de sí”. Michel Foucault, Tecnologías del yo (España: Paidós, 1990), 50-51. Este término fue transformándose en el cristianismo, Foucault dice: "Cada persona tiene el deber de saber quién es lo que está pasando dentro de sí, de admitir las faltas, reconocer las tentaciones, localizar los deseos, y cada cual está obligado a revelar estas cosas o bien a Dios, o bien a la comunidad, y por lo tanto, de admitir el testimonio público o privado sobre sí [...] Este vínculo permite la purifícación del alma, imposible sin un conocimiento de sí mismo". Ibid., 81.

${ }^{4}$ El término "biopolitica neumática" está tomado del artículo de Carlos A. Jáuregy y David Solodkow, "Biopolitics and the Farming (of) Life Bartolomé de Las Casas", en David Thomas Orique, O. P. y Rady Roldán-Figueroa (eds.), Bartolomé de las Casas, O. P. History, Philosophy and Theology in the Age of European Expansion (Leiden-Boston: Brill, 2019), el cual, se refiere a la gubernamentalidad o control sobre la vida espiritual de las personas. En el caso de mi objeto de estudio, es legítimo su empleo al referirnos al control del poder pastoral sobre la conducta de las mujeres de vida conventual, mientras que los autores citados aquí lo hacen para referirse a las poblaciones indígenas en las Indias durante el siglo XVI.
} 
La intención de toda la obra del filósofo francés fue "buscar cuáles son las formas y las modalidades de la relación consigo mismo por las que el individuo se constituye y se reconoce como sujeto", 5 de manera análoga, nuestro trabajo empleará como objeto de estudio específico los modelos de vida ascética femenina esperados en la vida conventual a través de un sermón escrito a finales del siglo XVIII por el del arzobispo de Burgos, Don Joseph Xavier Rodríguez de Arellano, consejero del Rey de España en 1780. Escogimos este por tratarse de máximas espirituales dirigidas a las monjas de sus órdenes religiosas; de todas las máximas que encontramos ahí, nos interesan exclusivamente los dedicados al buen y mal uso de la escritura. En ellos observamos dos casos emblemáticos interesantes, la práctica poética de Santa Teresa de Jesús, española del siglo XVI y la de sor Juana Inés de la Cruz del siglo XVII. ${ }^{6}$ Don Joseph hablará de estas dos poetas para utilizarlas como ejemplos de modelos correctos e incorrectos de función poética en la vida conventual.

La metodología empleada fue mixta, una documental de archivo basada en la revisión de fondos bibliográficos antiguos y otra teórica, de corte filosófico. De los acervos de fondos conventuales antiguos, encontramos un sermón en los acervos documentales del Museo Franz Mayer en la Ciudad de México, en particular su fondo conventual, ${ }^{7}$ que nos sirvió como objeto de estudio específico. No obstante, dicho sermón

\footnotetext{
${ }^{5}$ Michel Foucault, Historia de la sexualidad (España: Siglo XXI, 1993), 2:9.

${ }^{6}$ Sabemos que las reglas conventuales de las órdenes a las que pertenecían estas dos religiosas eran distintos, una Santa Teresa de Jesús fundadora, en 1562, de la orden de las Carmelitas Descalzas en España y cuyo testimonio lo encontramos en sus Constituciones escritas en 1563. La otra, sor Juana Inés de la Cruz, monja de la orden de San Jerónimo, quien vivió en la Nueva España en un ambiente cultural distinto al de la España del siglo XVI imbuida por reformas espirituales y en el terror del contagio luterano, lo que dio lugar a una gran persecución en contra de místicas y visionarias acusadas de alumbradismo, la misma Santa Teresa fue víctima de escrutinio. A diferencia de este ambiente, en el Barroco novohispano del siglo XVII al que pertenecía sor Juana, el miedo al luteranismo fue expresado sólo a nivel de la retórica. Véase Alicia Mayer, Lutero en el Paraíso (México: Instituto de Investigaciones Históricas, UNAM / Fondo de Cultura Económica, 2008), 45. La manera de composición de la poesía es distinta, las separa un siglo de distancia y un océano. No es nuestra intención establecer una secuencia histórica entre ambas poetas, sino referir a una comparación hecha por Don Joseph en este sermón, quien no está interesado en esas diferencias culturales, tampoco en el estilo de escritura poética ni en el contexto histórico en el que a ambas les toca vivir, le es indiferente, lo que busca es un impacto moral en las Carmelitas Descalzas del siglo XVIII a través de la retórica.

${ }^{7}$ Este fondo se conforma por un total de 420 impresos encuadernados en pergamino que abordan aspectos religiosos, científicos y literarios, provenientes de diferentes órdenes religiosas. Se trata de una serie de encuadernaciones en pergamino que pertenecieron a distintas órdenes religiosas españolas y novohispanas (su marca de fuego nos indica la orden a la que pertenecieron). Principalmente, encontramos pastorales, sermones,
} 
no es inédito, lo podemos encontrar en otros fondos antiguos internacionales, como es la Biblioteca Nacional de España. ${ }^{8}$ Esta investigación no pretende adentrarse en el campo de la historiografía, sino en el hermenéutico, en particular, la hermenéutica del yo de Michel Foucault, ya que si bien existen una multiplicidad de investigaciones de corte histórico dedicadas al estudio de la vida conventual femenina en la Nueva España muy amplia desde hace más de 50 años, ${ }^{9}$ frente a ellos, la originalidad de este trabajo consiste en efectuar un análisis teórico-filosófico sobre estas prácticas conventuales femeninas en la Nueva España desde las categorías filosóficas de Michel Foucault propuestas aquí, por ello la metodología no es historiográfica, sino hermenéutica filosófica sobre un objeto de estudio de valor histórico.

catecismos, exégesis del Antiguo y Nuevo Testamento, reglas de órdenes religiosas como franciscanos, jesuitas y carmelitas, así como varios compendios que abordan aspectos religiosos y científicos.

${ }^{8}$ El Fondo de Archivo del Museo Franz Mayer tiene un tomo original, que fue el que revisamos. El Fondo Conventual Antiguo de la Biblioteca Nacional de España (BNE) conserva nueve sermones escritos por el arzobispo de Burgos y consejero del Rey, Don Joseph Rodríguez de Arellano, dedicados a las monjas de Carmelitas Descalzas que pertenecen a su congregación, de finales del siglo XVIII. En el mercado, esta obra está muy cotizada por coleccionistas y su precio oscila entre los 230 y 250 euros. Los sermones antiguos son muy cotizados y algunos cuestan hasta 2,300 euros.

${ }^{9}$ Existe un amplio campo de estudios de vida conventual femenina en la Nueva España del siglo XVII, sólo revisaré algunos ejemplos tomados de las investigaciones de Josefina Muriel, Cultura femenina novohispana (México: Universidad Nacional Autónoma de México, 1982), y Asunción Lavrin, Las esposas de Cristo: la vida conventual en la Nueva España (México: Fondo de Cultura Económica, 2016), sin querer ser injusta con otros investigadores sobre el tema, porque el objetivo de nuestro trabajo es mostrar el ejercicio de prácticas de "tecnologías del yo" en las prácticas ascéticas de las monjas novohispanas del siglo XVII y la política pastoral en torno a la escritura poética de las monjas mediante un sermón del siglo XVIII. Desde luego se puede escribir un libro entero sobre casos específicos de monjas en la Nueva España, a partir de la amplia historiografía sobre vida conventual femenina novohispana. Por mencionar solo algunos de ellos, tenemos los trabajos de: Pilar Gonzalbo, Las mujeres en la Nueva España, educación y vida cotidiana (México: El Colegio de México, 1987); María Concepción Amerlick y Manuel Ramos, Conventos de monjas: fundaciones en el México virreinal (México: Grupo Condumex, 1995); Antonio Rubial, Monjas, cortesanos y plebeyos: la vida cotidiana en época de Sor Juana (México: Taurus, 2012); Doris Bieñko de Peralta, "Voces del claustro. Dos autobiografías de monjas novohispanas del siglo XVII", Relaciones: Estudios de historia y sociedad, 35, núm. 139 (junio-agosto, 2014), estudia a la monja jerónima María Magdalena (1575-1636) y a la carmelita Francisca de la Natividad (¿?-1658), de particular interés para nosotros porque analiza el papel de los confesores en los relatos autobiográficos de las monjas novohispanas del siglo XVII; Alma Montero, Monjas coronadas: profesión y muerte en Hispanoamérica virreinal (México: Museo Nacional del Virreinato / Plaza y Valdés, 2008). Con respecto a las visionarias y místicas entre las carmelitas descalzas, referidos a Santa Teresa de Jesús y su influencia en la Nueva España, está la cuidadosa y reciente edición de Jessica Ramírez Méndez y Mario C. Sarmiento Zúñiga (coords.), La presencia de la orden del Carmen Descalzo en la Nueva España. Interacciones, transformaciones y permanencias (México: Instituto Nacional de Antropología e Historia, 2019).

www.enclavesdelpensamiento.mx

https://doi.org/10.46530/ecdp.v0i30.408 
En cuanto a la metodología teórica, nos interesó en particular el concepto de 'biopolítica' de Foucault, quien la define como "[1]a introducción de una práctica gubernamental $[\ldots]$ en donde los sujetos aparecen como una población que el gobierno debe manejar". ${ }^{10}$ En particular nos interesa la técnica de poder ejercida por la política pastoral sobre la vida conventual, que es la práctica de poder más antigua, como la explica Foucault en sus conferencias dictadas en los años ochenta y que fueron recogidas en un libro titulado El poder: cuatro conferencias.

La implantación del poder pastoral ${ }^{11}$ sobre la vida de las mujeres en los virreinatos americanos — desde el siglo XVI al XVIII — estaba naturalizada como parte de la mentalidad de la época, es decir, el cuerpo de la mujer representaba para los hombres desafíos, luchas, debilidades y retos que tenían que apaciguar, por ello, se pueden considerar cuatro tipos de políticas de control, según Carlos A. Jáuregy y David Solodkow:

1) Políticas de multiplicación de las indias a través de la nutrición, higiene y reproducción sexual, la indumentaria, el manejo del cuerpo, el peinado y el matrimonio.

2) Políticas económicas coloniales para la explotación "humanitaria" del trabajo de las mujeres según una división según sexo y casta.

3) Políticas para el cultivo de la vida espiritual (pneumo-política o biopolítica neumática).

4) Política educativa. Los saberes colonizados y su reproducción en los estamentos sociales. Podemos incluir dentro de estas, a la educación estética a través del teatro, la literatura y las hagiografías de vidas de santas como modelos de vida ética y ejemplar. ${ }^{12}$

Nos centraremos en el tercer tipo de políticas, las destinadas al cultivo de la vida espiritual femenina novohispana del siglo XVII en un análisis crítico conocido como "biopolítica neumática".

\footnotetext{
${ }^{10}$ Michel Foucault, Nacimiento de la biopolítica (Buenos Aires: Fondo de Cultura Económica, 2007), 40-41.

${ }^{11}$ El poder pastoral es una de las formas más antiguas de poder que trata Foucault en varios libros, uno de ellos dice: "En el cristianismo, el nexo con el pastor es un nexo individual, un nexo de sumisión personal". Michel Foucault, El poder: cuatro conferencias (México: Universidad Autónoma Metropolitana, 1989), 54, 12 Jáuregy y Solodkow, “Biopolitics”, 127-166. 


\section{Metodología y objeto de estudio}

La metodología de análisis se construyó a partir de la estructuración teórica realizada en un trabajo previó — "Biopolíticas colonialistas en las Nahuas de la Nueva España en el siglo XVI"- en el cual se utilizó de la teoría de Michel Foucault en el Nacimiento de la Biopolítica, Hermenéutica del sujeto, e Historia de la sexualidad, pero aplicado a un objeto de estudio distinto, al igual que en éste, se tomaron tres de las categorías centrales del filósofo francés para elaborar la crítica de las prácticas del cuidado del cuerpo y del alma en la vida conventual - "la biopolítica, la tecnología del yo y el concepto de la carne para el cristianismo"-,${ }^{13}$ para luego utilizarlas en el análisis de dos casos emblemáticos de prácticas de control sobre la vida conventual: 1) las prácticas de racionalidad o gubernamentalidad ascética en la vestimenta, lenguaje, sexualidad y espiritualidad de las religiosas; 2) las técnicas de interiorización y de examen de conciencia a través de la confesión ${ }^{14}$ y la escritura en los claustros, en particular en dos modelos de escritura poética, Santa Teresa de Jesús y sor Juana Inés de la Cruz.

Se analizarán casos escogidos de la función de la escritura en los claustros novohispanos en el siglo XVII a partir de la categoría de "tecnologías de interiorización", los modelos de religiosidad ascética promovidos en el libro de máximas y consejos del arzobispo dirigidos a las monjas de clausura de la congregación de las Carmelitas Descalzas. Nos enfocaremos en la función de este sermón de finales del siglo XVIII y lo analizaremos a la luz de las categorías foucaultianas.

En las monjas novohispanas del siglo XVII observamos un acatamiento activo y voluntario en las prácticas sobre su propio cuerpo y sus pensamientos, para lograr la autoproducción de su conciencia de sí y la construcción de su subjetividad. Las prácticas de control de la sexualidad femenina novohispana más comunes eran el ascetismo, la abnegación, el autoexamen de conciencia - a través de la confesión de las faltas y pecados, los ejercicios de espiritualidad y los diarios de mujeres destinados a la confesión de las

\footnotetext{
${ }^{13}$ Cfr. María Cristina Ríos Espinosa, "Biopolíticas colonialistas en las Nahuas de la Nueva España en el siglo XVI", Revista Reflexiones Marginales, núm. 9 (junio, 2020), https://revista.reflexionesmarginales.com/biopoliticas-colonialistas-en-las-nahuas-de-la-nueva-espana-enel-siglo-xvi/.

${ }^{14}$ Ibidem.
} 
faltas. Esta forma de escritura fue ordenada por el poder pastoral para lograr una vigilancia eficiente de la conciencia y la conducta de las mujeres, fomentar modelos ejemplares de espiritualidad femenina y mantenerlas dentro de la ortodoxia religiosa. Doris Bieñko reconoce este control en la escritura conventual femenina, al afirmar: "[s]e escribía, como ya lo han notado algunas investigadoras, 'por mandato' de un superior o del confesor, quien al mismo tiempo fungía como censor y a veces como editor de los textos de su confesada. También se invocaba la licencia de Dios para tal actividad". 15

Las experiencias de las visionarias y místicas al interior de los claustros fueron sometidas a un estricto escrutinio para evitar el contagio del luteranismo, más difícil fue controlar a las seglares, por no estar sujetas al voto de obediencia ni a una regla conventual. No obstante, sí existieron controles inquisitoriales como fue el caso de la escritora neoplatónica Ana de Zayas, ${ }^{16}$ seglar de la ciudad de Puebla de los Ángeles, quien producía manuscritos de ejercicios espirituales y los regalaba a sus confesores, a quienes escandalizó por su heterodoxia y provocó que la denunciaran ante el Tribunal en 1694 acusada de alumbradismo.

Nos llama la atención la adopción voluntaria de las monjas de estas prácticas de ascetismo radical sobre su cuerpo, como muestra en sus ejemplos Lavrin, lo que les permitió obtener un conocimiento de sí mismas, como el precio que tuvieron que pagar para obtener su subjetividad, como dice Michel Foucault en Tecnologías del yo, el sujeto estuvo dispuesto a pagar un precio ascético de la razón; en el caso de las religiosas consistió en una negación del cuerpo y desprendimiento del mundo para acceder a una producción de verdad acerca de sí mismas. La manera de probarlo es a través de la adopción voluntaria de los votos de clausura de la orden por parte de las monjas, como fueron la obediencia, la castidad y el ascetismo.

\footnotetext{
${ }^{15}$ Bieñko de Peralta, "Voces", 158.

${ }^{16}$ Véanse los expedientes de Ana de Zayas en los archivos inquisitoriales del Archivo Histórico Nacional de Madrid, 1731, exp. 34 y en el Archivo General de la Nación de la Ciudad de México, 696, exp. 2, folio 287; así como las investigaciones de los historiadores expertos en el movimiento de los alumbrados tanto españoles como mexicanos, como Adriana Rodríguez y Fernando Ciaramitaro, "Alumbradas e ilusas de Nueva España. Un estudio a través de la documentación del Santo Oficio", Revista de Inquisición. Intolerancia y Derechos Humanos, núm. 20, (2016): 109-130; y en particular a Concepción de Zayas doctora en Historia de América en España, la mayor biógrafa de Ana de Zayas, en Ana de Zayas: escritora y maestra del espíritu. Heterodoxia y neoplatonismo en una seglar de la Puebla de los Ángeles (siglo XVII) (México: Benemérita Universidad Autónoma de Puebla, 2017).
} 


\section{"Tecnologías del yo" en la vida conventual femenina novohispana del siglo XVII}

La técnica de poder inaugurada por el cristianismo tridentino en los virreinatos americanos se dio a través de lo que Foucault llamó, tecnología de interiorización: la técnica de toma de conciencia, vigilancia de uno por sí mismo con relación a sus debilidades y sus propias tentaciones, ante la propia carne. ${ }^{17}$ Es así como, según Foucault, el cristianismo hizo funcionar esta moral que permitió la sujeción del individuo por sí mismo; éste fue el efecto de la introducción del poder pastoral del cristianismo individualizante desde la sociedad romana hasta nuestros días.

Para Foucault la producción del saber del individuo en el "conocimiento de sí mismo" y la "conciencia de sí" fueron los efectos del significado de la carne en el cristianismo $^{18}$ que, aplicado a nuestro objeto de estudio, fue el control de la sexualidad como base de la producción de la subjetividad interior de las mujeres en la Nueva España durante el siglo XVII. Ello posibilitó la producción de verdad de un discurso, entendido como la producción de la subjetividad y cuyo fundamento fue la sexualidad autorreprimida de las mujeres, que implicó una gran vigilancia de la conducta, los pensamientos y la imaginación.

La escritura fue por encargó de los confesores sólo en casos muy específicos: cuando la monja mostraba habilidades intelectuales para ello; se convirtió en una forma de vigilancia para mantener las técnicas espirituales femeninas dentro de la ortodoxia de la Contrarreforma y reforzar el examen de conciencia y autoconocimiento del alma tanto de religiosas como de seglares. En el caso de las religiosas, el ascetismo fue radical al respetar el voto de obediencia hacia las reglas de su congregación y a su confesor, quien les obligaba a llevar un cuaderno de examen de conciencia, donde debían anotar sus pecados y servía como modo de autocontrol de los deseos, en particular de los relacionados con los placeres del cuerpo y de la carne en el sentido referido. En otros casos, la escritura sirvió para la publicación de

\footnotetext{
${ }^{17}$ Véase el capítulo "Sexualidad y poder" de Foucault, Obras esenciales (Madrid: Paidós, 1999), 810-811.

${ }^{18}$ Michel Foucault es quien habla de la experiencia cristiana de la carne, lo que le interesó de esta experiencia fue como a través de esta experiencia el sujeto puede reconocerse como sujeto de deseo, se constituye como sujeto a través de su sexualidad, y estudia el cristianismo solo como ejemplo emblemático de cómo se ejerció ahí un mecanismo de poder que permitió producir una subjetividad a partir de la sexualidad y su regulación (Cfr. Foucault, Historia de la Sexualidad, 2:9; y Foucault, Obras esenciales, 800-814).
} 
biografías de las monjas en los claustros como modelos de vida ejemplar y guías de buena conducta para el resto de las mujeres en la sociedad novohispana. Otra de las funciones de la escritura, muy importante, fue la poética. El ejercicio de la poesía era correcto si iba encaminado a mejorar y acrecentar el amor por lo sagrado; en cambio, la poesía secular destinada al mero placer de versificación o a la agudeza del ingenio era censurada por conducir a la vanidad, a la necedad y al apego a lo mundano.

Todas estas prácticas ascéticas sobre el cuerpo y el uso de los placeres en la vida conventual se pueden incorporar en la categoría foucaultiana de "gubernamentalidad". Foucault al revisar lo que Guillaume de la Perrière entendía en 1555 por el arte de gobernar en El espejo político, que contiene diversas maneras de gobernar, afirma que se extiende al "modo de gobernar una casa, niños, almas, una provincia, un convento, una orden religiosa, una familia". ${ }^{19}$ Foucault está de acuerdo con De la Perrière, porque mucha gente gobierna, y "[e]l padre de familia, el superior de un convento, el pedagogo y el maestro con relación al niño o al discípulo". ${ }^{20}$ De esta manera, Foucault es partidario de revisar éstas otras maneras muy singulares de gobierno, radicalmente opuestas a las que retrata Maquiavelo en $E l$ Príncipe, y en su intención de retratar las distintas tipologías de gobierno, revisa a François de la Mothe Le Vayer, quien afirma la existencia de tres tipos de gobierno: “el gobierno de sí mismo que compete a la moral; en segundo lugar, el arte de gobernar una familia como es debido, que compete a la economía y, por último, la ciencia de gobernar bien el Estado, que compete a la política". ${ }^{21}$

Esta noción de "gubernamentalidad" foucaultiana es adecuada para nuestro objeto de estudio, para mostrar el ejercicio de la técnica de poder pastoral en la vida conventual femenina del siglo XVII, como muestran las investigaciones de Muriel y Lavrin, el control del cuerpo, técnicas de interiorización del alma, practicadas de manera voluntaria por las mujeres en los conventos novohispanos, así como el control de los confesores hacia sus "hijas espirituales" en la producción de la escritura, en particular la poesía, como mostramos en este sermón del siglo XVIII.

Podemos observar diversos tipos de escritura en los claustros: la primera, las descripciones de experiencias visionarias y místicas de las monjas; la segunda, el autoexamen de conciencia mediante diarios escritos por las monjas y la tercera, la

${ }^{19} \mathrm{Cfr}$. Michel Foucault, Estética, ética y hermenéutica, en Obras esenciales, 841.

${ }^{20}$ Ibid., 841.

${ }^{21}$ Ibid., 842. 
escritura poética, su finalidad fue el control de sus directores espirituales para mantenerlas dentro de la ortodoxia y para construir modelos femeninos virtuosos.

Existe una gran producción historiográfica sobre la vida de las mujeres en la sociedad novohispana, de entre ellos elegimos los de la investigadora Josefina Muriel, por sus trabajos pioneros en el ramo y ser una de los máximos exponentes en México en el análisis de vida conventual femenina en la Nueva España. Sostiene la persistente observancia pastoral masculina en las experiencias místicas contenidas en los diarios religiosos de mujeres en los siglos XVII y XVIII, para censurar cualquier tipo de falsa mística o fingidora, porque los directores espirituales "para poder conocerlas mejor les ordenaban que escribieran sus experiencias", ${ }^{22}$ no para conservar el registro de la experiencia en sí, sino para no caer en una errónea comprensión de la vida religiosa.

Asimismo, Muriel sostiene que los confesores fueron los responsables de que no conozcamos en su totalidad los escritos de las monjas acerca de sus vivencias. Ciertamente, no eran manuscritos destinados a su publicación, aunque existieron algunas excepciones, sólo salieron al público las partes que interesaban a los religiosos para realizar una biografía, en particular si se trataba de una monja perteneciente a su propia congregación, por cierto, siempre escrita por un varón. "Fue ese paternalismo clerical prepotente muy de época el que no dio valor literario a los escritos místicos femeninos y las refundió en el polvo de los archivos", ${ }^{23}$ es por ello que muchas apelaron a la intervención divina para proteger en gran medida sus escritos y sus experiencias. En el caso particular de la seglar visionaria Ana de Zayas, el mismo obispo Manuel Fernández de Santa Cruz apela a la locura de esta acusada para defenderla y evitar pisar las cárceles de la Inquisición, mientras que ella sí afirma la certeza de la infusión divina recibida en sus experiencias místicas y nunca se desdice ante sus acusadores, no se caracteriza por su sumisión.

Asunción Lavrin, en la vida conventual en la Nueva España en Las esposas de Cristo. La vida conventual en la Nueva España, expone cómo la subjetivación femenina consistió en una ascética del cuerpo como pago para obtener el conocimiento de sí mismas y de Dios a través de la unión mística, ello requirió una técnica de interiorización del alma, para lograrlo fue necesario someter el cuerpo a la voluntad del espíritu y eso fue

\footnotetext{
${ }^{22}$ Muriel, Cultura, 317.

${ }^{23} \mathrm{Ibid} ., 317$.
} 
lo que significó la fortaleza del alma o del espíritu que encontramos también en algunos escritores griegos y romanos, como Epicuro, Séneca y Cicerón.

La confesión y la comunión formaron parte de la técnica de interiorización de la subjetividad femenina, permitía a la monja purificar su conciencia de pensamientos impuros y mal comportamiento para obtener la absolución y la comunión. "La Iglesia prescribía un número mínimo de confesiones anuales para las personas laicas, pero las monjas podían confesarse siempre que sintiesen la necesidad de aliviar su espíritu. [...] Toda experiencia de amor; deseo o afecto era reprimida o sublimada por su amor a Cristo". ${ }^{24}$

El amor por un hombre era pecaminoso y producto de un engaño del diablo; son múltiples los casos de transgresión de los confesores que veían en sus hijas espirituales un objeto de deseo, los archivos inquisitoriales relatan varios casos, los cuales han sido poco estudiados hasta ahora.

\section{Escritura femenina como "conocimiento de sí"}

En los escritos de Foucault acerca de "La hermenéutica del sujeto" nos dice que la hermenéutica del yo consistió en una serie de prácticas muy antiguas que en griego se conocieron por epiméleia heautou y en latín cura sui, en castellano significa "cuidado de sí", "ocuparse de sí" pero ello está asociado al "conocimiento de sí" [gnothi seautón]: "Pero hay que recordar que la regla según la cual hay que conocerse a sí mismo ha estado regularmente asociada al tema del cuidado de sí. De un extremo al otro de la cultura antigua es fácil encontrar testimonios de la importancia concedida al cuidado de sí y de su conexión con el tema del conocimiento de sí". ${ }^{25}$ Foucault analiza a varios fílósofos de la antigüedad como fueron Sócrates, Gregorio de Nisa y Epicuro, entre otros, para ejemplificar aquello a lo que se refiere con el "cuidado de sí mismo" y concluye que es una práctica y una actividad: "un deber y como una técnica, una obligación fundamental y un conjunto de procedimientos cuidadosamente elaborados". ${ }^{26}$

\footnotetext{
${ }^{24}$ Ibid., 289.

${ }^{25}$ Foucault, Estética, ética y hermenéutica, 925-936.

${ }^{26}$ Ibid., 927. 
Del análisis de estos casos nos interesa retomar la noción de "cuidado de sí", de Gregorio de Nisa, que aparece en su Tratado de la virginidad, sobre la relación entre alma y cuerpo, la parábola del dragma. Ésta es la manera como el ascetismo cristiano se relacionó con el "conocimiento de sí" y el "cuidado de sí". Para este cristianismo antiguo, "el cuidado de sí" era algo relativo: "al movimiento por el que se renuncia al matrimonio, se pierde el apego a la carne y por el que, gracias a la virginidad del corazón y del cuerpo, se recobra la inmortalidad del alma de la que habíamos sido desposeídos". ${ }^{27}$ Nos interesa esta noción porque es análoga a la que se vivía en el mundo conventual novohispano en el siglo XVII y como las religiosas concebían esta relación entre cuerpo, alma e inmortalidad.

Otras nociones foucaultianas adecuadas para analizar las técnicas de interiorización y de examen de conciencia en las prácticas de vida conventual novohispana son las relativas a lo que Foucault llama "ascesis" de la verdad, a saber, la importancia de la escucha, el autoexamen anakhóresis eis heauton, volverse a uno mismo, hacer examen de las "riquezas ahí depositadas", y, por último, la escritura, Foucault dice: "la escritura personal: tomar notas sobre las lecturas, las conversaciones y las reflexiones que se escuchan o que uno se hace a sí mismo; tener una especie de libreta de apuntes sobre los temas importantes (lo que los griegos llamaban hypomnémata) y que debían ser leídos cada cierto tiempo para reactualizar sus contenidos". ${ }^{28}$ Este conjunto de técnicas practicadas al interior de los conventos femeninos novohispanos nos sirven de evidencias para probar el vínculo entre la verdad acerca de una misma y el sujeto, en el sentido de dotar a la subjetividad femenina de una verdad desconocida, el conocimiento de su amoroso esposo Jesucristo. Asunción Lavrin experta en vida conventual femenina novohispana, nos dice que:

La Iglesia católica tuvo una larga tradición de mujeres escritoras antes y después del movimiento de Reforma [...] Tanto en la Edad Media europea como desde el siglo XVI en adelante, las mujeres plasmaron por escrito sus experiencias espirituales íntimas, formando un corpus significativo [...] España llegó un poco tarde a la escena de los escritos femeninos místicos y literarios, pero hacia fines del siglo XVI ya existía una

\footnotetext{
${ }^{27}$ Ibid., 926.
}

${ }^{28}$ Ibid., 933. 
corriente de composición de mujeres religiosas y laicas que servirían como modelo que habitaban al extremo del Atlántico. ${ }^{29}$

Lavrin sostiene que los hombres no consideraban a las mujeres hábiles para la tradición escritural, pero es verdad que las mujeres produjeron su subjetividad a partir de la escritura como forma ascética de purificación espiritual, práctica ligada a otras formas como la confesión, oración, mística, escucha y confesión; represión sobre el cuerpo como ayunos, flagelaciones, sacrificios también para la limpieza del alma. La Inquisición estuvo encima de las mujeres escritoras en el siglo XVI en España y en el XVII en la Nueva España, pero una vez que Teresa de Ávila fue incluida y legitimada dentro de mística ortodoxa se utilizó como modelo de religiosidad ejemplar y aparece en sermones y consejos espirituales de los religiosos pertenecientes a las órdenes de los Carmelitas Descalzos y de los jesuitas en el siglo XVIII, como lo muestra el sermón del siglo XVIII del que hablaremos más adelante.

Los hombres impedían las publicaciones de escritos femeninos y controlaban la expresión intelectual femenina por desafiar su hegemonía. Esta situación se modificó después de la santificación de Teresa de Ávila y permitió que en la Nueva España algunos teólogos, en particular jesuitas, favorecieran la escritura femenina en los conventos durante el siglo XVII. Tal es el caso de Alonso Ramos, quien a finales del siglo XVII encarga la escritura de una hagiografía dedicada a Catalina de San Juan, monja novohispana de la orden de los dominicos y de quien promovió su santificación por haber sido su último confesor, encargó a varias mujeres un escrito sobre la venerable monja, incluso se lo pidió a la polémica neoplatónica Ana de Zayas, contemporánea de sor Juana Inés de la Cruz. La seglar de Puebla tuvo abierto un proceso inquisitorial a mediados del siglo XVII por sus manuscritos espirituales que regalaba a sus confesores para enmendarles la práctica espiritual, y algunos de ellos fueron sus denunciantes.

Cuando la escritura comenzó a florecer en el siglo XVII en la Nueva España, lo hizo bajo restricciones significativas. Las monjas escritoras del siglo XVII lo hicieron bajo el anonimato detrás de los muros de sus instituciones y ocultas al público lector, mientras

${ }^{29}$ Lavrin, Las esposas, 394-395. 
que los autores hombres utilizaban sus notas biográficas y recuerdos conventuales para publicar crónicas y biografías. ${ }^{30}$

Sabemos que sor Juana Inés de la Cruz fue una excepción, pero no es casual que sus obras hayan sido impresas en España en 1689 y no en la Nueva España, gracias al apoyo de su amiga y admiradora María Luisa Gonzaga Manrique de Lara, condesa de Paredes, marquesa de La Laguna y exvirreina de la Nueva España. Nos preguntamos, ¿por qué no se publicaron en la Nueva España? Pudo ser por las redes de comunicación transatlántica de la poeta novohispana, sus amistades poderosas, o bien, por la falta de confianza en la habilidad intelectual de las mujeres para las tareas escriturales y literarias, considerado un oficio plenamente masculino.

Existió otro tipo de escritura en los conventos, la relacionada con el examen de conciencia de la religiosa y su confesor, en éste nos centraremos para mostrar las prácticas de las tecnologías de interiorización de las mujeres.

A pesar de sus afirmaciones retóricas de no desear escribir, las monjas acababan por sublimar esa labor como una forma aceptable de "sufrimiento", siempre apreciable para el estado religioso. A través de la escritura desahogaban su conciencia en un proceso afín a la autoconfesión y aclaraban sus dudas sobre su vida y necesidades espirituales. Requerían de un interlocutor que les permitiese abrir sus almas y encontraban en el confesor a esa persona. ${ }^{31}$

Las autoridades eclesiásticas reflexionaron profundamente sobre los escritos místicos; tal es el caso de la carmelita Isabel de la Encarnación, quien profesó en 1613. Lavrin nos muestra cómo fue sometida a exorcismos por parte de sus confesores y tuvo que ser defendida por el reconocido teólogo irlandés Miguel Godínez, quien escribió su biografía y la de su compañera Francisca de la Natividad. ${ }^{32}$ Los escritos hagiográficos de santas y de biografías femeninas fueron promovidos por los jesuitas en su gran mayoría, pero estuvieron también bajo el escrutinio de la Inquisición.

\footnotetext{
${ }^{30}$ Ibid., 396.

${ }^{31}$ Ibid., 399.

${ }^{32}$ Cfr. Bieñko de Peralta, "Voces", 168; estudia la autobiografía de la carmelita Francisca de la Natividad y su relación con Miguel Godínez, dice en la nota 21: "La discreción o el discernimiento del espíritu fue un proceder frecuente en los casos de las experiencias místicas, que no se limitaba solo a exigir que tales experiencias fuesen escritas, con fin de que fuesen analizadas, sino que también involucraba la observación cotidiana del comportamiento del visionario, por parte de terceros (testigos y confesores)".
} 
La referencia de Lavrin sobre la escritura femenina en los conventos novohispanos es para mostrar la gran afectividad emocional entre el confesor y su hija espiritual, y cómo muchas fueron admiradas por ellos y usaban la confesión para desahogarse. No es de nuestro interés concentrarnos en los vínculos emocionales entre ellos, sino la relación de las mujeres consigo mismas a través de sus diarios personales como medio para la construcción de su propia autoconciencia e identidad.

Los escritos autobiográficos de mujeres permanecieron en los archivos conventuales y sirvieron para que algunos notables jesuitas escribieran biografías de monjas, ${ }^{33}$ también con la finalidad de darle prestigio a la orden religiosa en los casos en los que el biógrafo perteneciera a la misma congregación, pero todo esto no excluye el hecho de que ellas usaran sus diarios íntimos para reflejar sus estados de conciencia, debilidades y prácticas ascéticas sobre su cuerpo y la purificación de su alma. Se conserva sólo un puñado, lo cual dificulta la investigación, pero muestran la evidencia de las prácticas.

\section{"Biopolítica neumática" en la producción de modelos de escritura conventual: Santa Teresa de Jesús y sor Juana Inés de la Cruz}

La escritura femenina estuvo permitida sólo para ejercicios espirituales, diarios destinados al examen de conciencia, que funcionaron como una mnemotecnia, útil para producir una mayor intimidad en la religiosa y un mejor "conocimiento de sí". ${ }^{34}$ A

\footnotetext{
${ }^{33}$ Véase el cuidadoso estudio de Bieñko de Peralta, "Voces", en torno a estas biografías encargadas por jesuitas.

${ }^{34}$ Este término es analizado por Foucault dentro de su desarrollo de la hermenéutica del yo, en el contexto tanto de la filosofía grecorromana en los dos primeros siglos a. C. del bajo imperio romano como en la espiritualidad cristiana, a partir de los principios monásticos que imperaron en el IV y V siglo del final del alto imperio romano. El "conocimiento de sí mismo" o el "conócete a ti mismo" era, según el filósofo: "El principio délfico $[\ldots]$ un consejo práctico $[\ldots]$ En los textos griegos o romanos, la exhortación al deber de conocerse a sí mismo estaba siempre asociada con el otro principio de tener que preocuparse de sí". Foucault, Tecnologías del yo, 50-51. Este término fue transformándose en el cristianismo, Foucault dice: "Cada persona tiene el deber de saber quién es lo que está pasando dentro de sí, de admitir las faltas, reconocer las tentaciones, localizar los deseos, y cada cual está obligado a revelar estas cosas o bien a Dios, o bien a la comunidad, y por lo tanto, de admitir el testimonio público o privado sobre sí [...] Este vínculo permite la purificación del alma, imposible sin un conocimiento de sí mismo". Ibid., 81.
} 
diferencia de este tipo de escritura conventual femenina, la poesía satírica o versificación en asuntos que no competían a lo sagrado fueron considerados distractores en los oficios de las monjas, y no sólo eso, sino verdaderas tentaciones del demonio. Un ejemplo de ello lo evidencian las publicaciones de manuales, ejercicios espirituales y consejos de los obispos y confesores a cargo de la práctica pastoral de una congregación religiosa de mujeres; como el caso del sermón siguiente, en donde se retrata la censura del arzobispo de Burgos, Don Joseph Xavier Rodríguez de Arellano, consejero del Rey de España en 1780, autor del libro Avisos Espirituales que dio a sus hijas espirituales la Seráfica doctora Santa Teresa de Jesús y explica en pláticas su devoto, el Ilustrísimo Señor Don Joseph Xavier Rodríguez de Arellano, Arzobispo de Burgos, del Consejo de su Majestad y dedica a sus veneradas preladas, religiosas de los monasterios de su filiación, las Carmelitas Descalzas españolas.

La función del sermón era meter en razón a través del uso del convencimiento emocional. Antonio Rubial sostiene que durante el siglo XVII la cultura impresa

estuvo vinculada con la oralidad, pues la retórica, el principal medio de la estructuración de los discursos, estaba básicamente dirigida a convencer a un público de escuchas [...] susceptibles de ser utilizados como instrumentos para dar una enseñanza moral [...] la retórica se proponía tres objetivos: enseñar comportamientos morales (docere), entretener (delectare) y provocar sentimientos de repudio o de admiración (movere). ${ }^{35}$

Con respecto a la existencia de fuentes secundarias que, al igual que Don Joseph hayan hecho una comparación entre las dos poetas, nos encontramos con los aportes de algunos contemporáneos, como Jean-Michel Wissmer, investigador de la Universidad de Ginebra, Suiza, quien las comparó en "Santa Teresa y Sor Juana: diálogo entre dos hermanas", ${ }^{36}$ y sostiene que fueron perseguidas: escogieron los votos de clausura para huir del matrimonio, gozaban de mala salud, y ambas poetas defienden a la mujer. El escritor suizo le objeta a Julio Jiménez Rueda (1896-1960) —escritor y diplomático mexicano- su declaración acerca de la imposibilidad de comparar a ambas poetas, en su discurso de ingreso en la Academia Mexicana “Santa Teresa y sor Juana, un paralelo imposible”. Por otro lado, Erika

\footnotetext{
${ }^{35}$ Antonio Rubial, El paraíso de los elegidos: Una lectura de la historia cultural de la Nueva España (1521-1804) (México: UNAM / Fondo de Cultura Económica, 2010), 30-31.

${ }^{36}$ Jean-Michel Wissmer, "Santa Teresa y Sor Juana: diálogo entre dos hermanas", Revista La Colmena, núm. 47 (julio-septiembre, 2005). http://web.uaemex.mx/plin/colmena/Colmena\%2047/Aguijon/Jean.html 
Martínez Cabrera, de la Universidad de Granada, en su ponencia presentada en el II Congreso Internacional CELEHIS de Literatura "Sor Juana y Santa Teresa: dos ventanas una luz”, sí encuentra paralelos, aun si a las dos monjas las separó un siglo y un océano:

¿Se enfrentaron Sor Juana y Santa Teresa a obstáculos similares en su particular vivencia del Siglo? Quizás en cierto sentido. Para empezar, si en el México del XVII la moral contrarreformista imponía normas severas y duras sanciones para enderezar las almas de su pequeña gran corte, en la España imperial del XVI el clima de ortodoxia y persecución no era menos, con una Inquisición que, en su lucha contra el protestantismo, miraba con malos ojos cualquier señal de fervor intimista. La propia institución conventual estaba organizada de manera similar en la metrópoli y el virreinato de Nueva España: sus estructuras jerárquicas garantizaban en la misma medida la tutela clerical y varonil sobre la intelectualidad femenina. A esta realidad podemos añadir las circunstancias personales de nuestras dos autoras, hija de converso una, hija ilegítima la otra, ambas usurpadoras del espacio masculino de la escritura y violadoras de la ley paulina del silencio. ${ }^{37}$

De igual manera, Silvia Hamui considera a Santa Teresa de origen judioconverso, y encuentra ahí las posibles razones de su misticismo y exacerbado cristianismo, una forma de tener presencia frente a un orden patriarcal y de limpiar o borrar su genealogía. "En ese sentido, nos podríamos preguntar ¿es el irreprochable catolicismo de Santa Teresa una reacción para poder ocultar su prosapia?, ¿su herencia judaizante implicaba esa búsqueda de nuevas formas de religiosidad para legitimar sus orígenes?". ${ }^{38}$ No estamos de acuerdo con Silvia Hamui en que ésta sea la razón de su vocación ni la de su misticismo, sino una firme elección de la monja de Ávila, pues la experiencia de vinculación mística es una fenomenología, una decisión de conciencia, de sed espiritual genuina como forma de estar en la existencia y la poesía mística es la manera de representar lo inefable. Santa Teresa nunca temió la persecución por sus visiones; al contrario, siempre estuvo dispuesta a pasar por su noche obscura para acceder a la iluminación, las expresó con valor mediante la poesía, lo mismo que a sus confesores, sin importarle las consecuencias.

En contraste, la poesía de sor Juana no es mística: Dios no es una experiencia íntima sino abstracta. La comparación entre ambas poetas en el sermón referido en

\footnotetext{
37 Erika Martínez Cabrera, "Sor Juana y Santa Teresa: dos ventanas una luz”, Ponencia II Congreso Internacional CELEHIS de Literatura (Argentina: Universidad Nacional del Mar de la Plata, Facultad de Humanidades, Centro de Lenguas Hispanoamericanas, 2004), 1-2.

38 Silvia Hamui, “Aspectos sobre la escritura mística”, en Jessica Ramírez y María C. Sarmiento Zúñiga (coords.), La presencia de la orden del Carmen Descalzo en la Nueva España. Interacciones, transformaciones y permanencias (México: Instituto Nacional de Antropología e Historia, 2019), 109.
} 
nuestra investigación es con finalidades retóricas, es decir, moralizantes, ésa es la intención del consejero del Rey al dirigirse a las monjas de su congregación. Don Joseph fue un gran devoto de Santa Teresa de Jesús a quien utiliza como ideal de buen comportamiento. Es la autoridad a la que recurre para poder justificar los consejos dirigidos a las monjas, cita pasajes enteros de sus obras más conocidas, Camino de Perfección y Las Moradas. Los Avisos [o Máximas Espirituales] contienen una serie de reglas de conducta prescritas acerca de lo que se debía hacer y evitar dentro de la vida conventual para alcanzar la perfección y cumplir las obligaciones que su amado esposo Jesucristo esperaba de ellas. El índice de este libro habla de una serie de observancias que él llama "avisos espirituales", en los que encontramos consejos de índole práctica como la correcta elaboración de oficios: la costura, la cocina y formas de conducta con reglas ascéticas claras sobre cuerpo y la espiritualidad virtuosa.

Dentro de estas máximas o consejos destinados a las monjas carmelitas, nos encontramos con una "biopolítica neumática", entendida como una técnica de poder pastoral y de control sobre la vida espiritual de las religiosas. La función de la poesía conventual femenina debería estar destinada al incremento de la devoción y de lo sagrado, la cual se debía emplear exclusivamente como un medio de perfección unitiva con Jesucristo.

Don Joseph dedica un prólogo muy interesante dirigido a las religiosas carmelitas, su análisis nos muestra las exigencias impuestas sobre ellas; en primer lugar, las va a comparar con las Tórtolas: es común en el Barroco del siglo XVII este tipo de analogías entre mujeres virtuosas y palomas. Así lo hace Francisco de Sales; Foucault hace referencia a este santo como ejemplo de la práctica de "tecnologías de poder" sobre la carne en el cristianismo, ${ }^{39}$ aunque para el caso que nos ocupa, una "técnica de interiorización" femenina. Don Joseph les dice a las monjas de su congregación de Carmelitas Descalzas lo siguiente:

Así lo considera vuestro Prelado con mucho consuelo suyo, y os contempla como Tortolas desviadas de los tumultos del mundo, enterneciendo al señor con sus gemidos, y como almas, que condujo el esposo à verdadera soledad para hablarlas al corazón. Así os considera y solicita así para que [...] gimais, suspireis y clameis a Dios por el remedio.

${ }^{39}$ Foucault, Estética, ética y hermenéutica, 882-883. 
No es libre en vosotras el atender este encargo y es obligación urgente, porque como decía María Magdalena de Pazzis. "Nosotras hermanas, hemos de dar cuenta a Dios de muchas almas, que hay en el Infierno, que si hubiésemos rogado a su Majestad por ellas, no se hubieran condenado. Este es nuestro oficio, porque Dios no nos ha sacado del mundo solo para que seamos buenas para nosotras, sino para ayudar con oraciones y penitencias a los demás. No olvidéis estos encargos, amadas vuestro principal cuidado, y emplead incesantemente vuestros devotos clamores en beneficio de la Iglesia, que adquirió vuestro Esposo con su Sangre". ${ }^{40}$

Luego de este recordatorio acerca de la elección ascética de vida y de renuncia al mundo, siempre en la búsqueda del ideal de perfección, va a comenzar a dar sus máximas espirituales dentro de las cuales incluye una censura a la creación poética.

La práctica de la composición poética con fines místicos se convirtió en un claro ejercicio de "biopolítica neumática", de control por medio de las prácticas espirituales y ascéticas del cuerpo, de negación de los placeres del mundo. En el Aviso XXVI titulado Nunca hablar sin pensarlo bien, y encomendarlo mucho à nuestro Señor, para que no hable cosa, que lo desagrade, el arzobispo va a dedicarse a argumentar acerca de si la poesía es una buena práctica o no, si verdaderamente es un ejercicio de perfección y dice: "La Poesía es un dulcísimo embeleso, que embarga las atenciones de tal modo, que si el Poeta no està siempre sobre si, no pensàra en otra cosa, que en versificar". ${ }^{41}$ Esta cita muestra cómo se consideraba a la práctica una distracción, pero también un placer para el cuerpo, en el sentido de embelesar la imaginación y ocupar la mente como una obsesión, ya que el poeta no pensará en otra cosa, se convertirá en una suerte de delirio o locura. No es una buena práctica según Don Joseph, porque distrae a las religiosas de sus deberes

\footnotetext{
${ }^{40}$ Joseph Xavier Rodríguez de Arellano, Avisos espirituales que dió a sus hijas la seráfica doctora Santa Teresa de Jesús, y explica en pláticas su devoto el ilustrísimo señor Don Joseph Javier Rodríguez de Arellano, Arzobispo de Burgos, del Consejo de su Majestad y dedica a las venerables preladas y religiosas de los monasterios de su filiación, vol. 2 (Burgos: Joseph de Navas, 1780), 2-3. Para el uso de las citas se siguió un criterio paleográfico. El sermón tenía la función retórica de ser utilizado como instrumento para dar una enseñanza moral, convencer y conmover a través de la elocuencia retórica. El arzobispo de Burgos utilizaba las cartas pastorales y los sermones para la predicación, nos encontramos con nueve escritos provenientes de su pluma, entre cartas pastorales y sermones ubicados en la Biblioteca Nacional de España, se encuentran referidos en la bibliografía, todos fechados entre 1766 a 1780, como este que hemos venido analizando. Hemos encontrado algunas fuentes secundarias mencionadas en notas anteriores, de investigadores que han analizado la relación entre Santa Teresa y sor Juana, monja novohispana del siglo XVII, las separa un siglo y un océano. Dichas fuentes establecen analogías entre ellas, más que establecer una oposición entre ellas, como hace este prelado Carmelita.

${ }^{41}$ Rodríguez de Arellano, Avisos, 453. De aquí en adelante todas las citas textuales de este manuscrito se dejaron en su escritura original.
} 
conventuales, como lo vemos en la siguiente cita: “Será esto bueno en quien no debe tener la atención desembarazada para las observancias de su Regla?". ${ }^{42}$

La asociación del amor por la poesía con la locura y la condena de su práctica excesiva como una vergüenza social, la encontramos en la siguiente afirmación: "el hombre de juicio debe ser, ni tan necio, que no haga un verso, ni tan loco, que haga dos [...] me contentaré con que qualquiera versificante tenga presente aquel adagio, la mucha conversación es causa de menosprecio [...] Y si se oyese en una Religiosa esta vulgaridad, ¿quànto no murmuraría el mundo y con razón?”. ${ }^{43} \mathrm{Y}$ es sobre este punto en donde menciona a sor Juana Inés de la Cruz, cuya fama, en la segunda mitad del siglo XVII, ya es mundial: la va a comprar con Santa Teresa de Jesús para censurarla.

La segunda parte del apartado XXVI de este sermonario está dedicada a la práctica de la poesía. Es interesante porque es un testimonio de lo que ocurría en la Nueva España. Se nota que España estaba bien enterada de las noticias del otro lado del Atlántico sobre la erudición de sor Juana y su producción literaria. Don Joseph critica duramente a la monja novohispana por su oficio de poeta; la pone como ejemplo de necedad, locura y vanidad; recomienda a las religiosas no distraerse con la versificación. La poesía es una mnemotecnia que funciona de la siguiente manera: si se elogia a alguien con el verso esto se le queda en la memoria, pero de igual manera si se emplea para satirizar a alguien, queda herido y resentido, de ahí que Don Joseph considere a la poesía un distractor de los deberes y obligaciones, principalmente en las religiosas. El uso correcto de la poesía sería el dedicado para cuestiones sagradas y de veneración religiosa, tal como lo hizo Santa Teresa de Jesús, a la cual elogia y pone como modelo de imitación femenina.

Según Don Joseph, si no es para fines devocionales la poesía es un distractor para necias, porque la monja se pierde más cazando coplas y seguidillas que en la observancia de su regla religiosa; para fundamentar su discurso, toma a sor Juana como ejemplo de necedad: "La Poesía es mucho bien, pero no tanto como la oración [...] mandada a toda religiosa, y no lo está la Poesía". ${ }^{44}$ Más adelante dice: "De suerte que al hacer versos

\footnotetext{
${ }^{42}$ Ibidem.

${ }^{43}$ Ibidem.

${ }^{44}$ Ibid., 455.
} 
fuese tropiezo para orar como se debe, faltará la religiosa [Sor Juana] à lo que debe si hace versos [...] porque no usándola bien es un VENENO MORTAL". ${ }^{45}$

De tal suerte que el hacer poético no debe sustituir a los deberes de la regla de observancia de una religiosa, porque se convierte en objeto de perdición del alma. En una intención dialéctica de su argumento, el arzobispo habla con sus opositores imaginarios al decirnos:

A esto se podrá oponer, que han tenido los Claustros insignes Poetizas, sin dejar de ser muy buenas Religiosas [...] Nunca se habla en el asumpto , que no salga à la conversación Sor Juana Inés de la Cruz, más conocida en el Mundo por el renombre de la Monja de Mexico (sic). Pero se hacen mucha necedad, quantos la citan en su apoyo. La comparación es mucha ofensa, es sumamente enorme la distancia, porque fuè una Mujer que embiò Dios à este mundo para nueva manifestación de su infinito poder, y para hollar las altanerías del sexo Varonil. ${ }^{46}$

Sin embargo, los hombres al citar la erudición de sor Juana no se dan cuenta que su crítica es a la altanería de los hombres, y no está de acuerdo en comparar a las religiosas buenas con las poetas. Si bien Don Joseph reconoce la gran erudición de sor Juana y nos da cuenta de los elogios y admiración que le tienen los notables, como el Marqués de Mancera, Virrey de aquellos Reinos, al final remata su comentario con una crítica a su admirable escritura: "Mucho argumento es este de su sabiduría. Pero es más convincente la humildad, con que salió de ese convate [...] aseguro haver salido con tan poca satisfacción de sí". ${ }^{47}$ Más adelante menciona: "Esto fuè Juana Inés en el siglo y todavía mas en la Clausura de su Monasterio. Antes de entrar en el Claustro daba todas las horas al estudio". ${ }^{48}$

La manera como el arzobispo habla de sor Juana es sarcástica, primero, la critica; después la elogia, y al final la deja precipitarse en el desprestigio de la censura. Un ejemplo de ello es la siguiente cita, en donde vemos como después de criticarla va a encumbrarla como un ejemplo de renuncia y devoción: "Esta Mujer [...] con una biblioteca de 4,000 cuerpos [...] entró en cuentas consigo". ${ }^{49}$ Sin embargo, estos

\footnotetext{
${ }^{45}$ Rodríguez de Arellano, Avisos, 455.

${ }^{46}$ Ibid., 457.

${ }^{47}$ Ibidem.

${ }^{48}$ Ibidem.

${ }^{49}$ Ibidem.
}

www.enclavesdelpensamiento.mx https://doi.org/10.46530/ecdp.v0i30.408 
elogios son parte del sarcasmo, pues después duda de la honradez de la intención de sor Juana, al decirnos:

¿Qué se debe inferir de esta resolución [...] ¿Què sabemos si tras la mucha aclamación iria algún ayre de vanidad [...] Era en aquel tiempo oráculo común. Todo se le consultaba, y a todo respondía [...] y aunque muy Religiosa, era mujer. No sería maravilla que el viento de los aplausos desmoronase el edificio de su abatimiento. ¿Qué sabemos si tras las muchísimas especies, que ocupaban su entendimiento y su memoria, ya en la Red y yá en la Celda, no quedarían presas en la Celda, y en la Red, y se atreverían à la Misa, al oficio, y la oración $?^{50}$

Más adelante, precisa: "Nació el 12 de noviembre de 1651 y murió el 17 de abril de 1695, a los 44 años [...] Luego si quando se mire à mejor luz, y entre à mejor luz, y entre à cuentas consigo toda Religiosa ha de desestimar semejantes harmonias, el no hacer esta diligencia desde luego es prueba de que aun no entró en cuentas consigo". 51

En esta cita podemos observar la verdadera opinión del arzobispo hacia sor Juana, de quien no considera honesta su intención: no cree que haya hecho cuentas consigo misma a través de un examen de conciencia para rectificar su conducta hacia la obediencia de sus tareas de religiosa de clausura. La juzga como alguien que perdía el tiempo en relaciones sociales con notables de la época y en las novedades de la moda literaria, el aplauso, la vanidad y, no obstante, renunció a sus libros, al estudio y a la escritura poética, todos esos conocimientos, duda Don Joseph, no los pudo olvidar; pues quién asegura no los llevaba a la misa y se distraía con conceptos a pesar de ya no dedicarse al estudio de los libros como antes. Todo este discurso reprobatorio era para persuadir a las Carmelitas Descalzas sobre lo que deben evitar para ser buenas religiosas, como un claro ejercicio de "biopolítica nemática".

Don Joseph utiliza en su argumentación dos modelos de práctica poética de escritoras reconocidas: Santa Teresa de Jesús, cuya poesía va dirigida a acrecentar la devoción, mientras que la de sor Juana Inés de la Cruz va encaminada a las muestras de ingenio y agudeza. Pareciéramos testigos de un certamen entre la fe y la razón, donde la primera triunfa sobre la segunda. Como podemos observar en la comparación que hace entre la poesía de estas dos religiosas; de Santa Teresa, nos dirá: “¿Se oyó, que desyrase su

\footnotetext{
${ }^{50}$ Ibidem.

${ }^{51}$ Ibid., 462.
}

www.enclavesdelpensamiento.mx https://doi.org/10.46530/ecdp.v0i30.408 
buen gusto, con estas diversiones? ¿Se le vió jamás en la Red para otra cosa, que para servir de edificación con un continuo exercicio de virtud?". 52 Es por esta comparación que sabemos que triunfó como modelo de práctica virtuosa la poesía devocional de Santa Teresa, a quien el arzobispo la relaciona socialmente (en la Red) sólo para ejercitar la virtud a diferencia de sor Juana dedicada a los placeres del juego del ingenio y la agudeza.

Id notando, Aquel Ingenio grande [se refiere a Sor Juana] que sabía también, como el más diestro, de cuantos primores es susceptible lo Poético, especialmente en lo Lyrico, la apellida Poetico Lyrico portento. Esto bastara en otra capacidad menos juiciosa [Teresa de Jesús] para derramar en más número, y variedad de Poesias, y para rendirse al ruego en amorosos y satíricos, y profanos. No lo hizo la Santa Madre [Teresa de Jesús] de este modo, siempre estuvo su instrumento [la poesía] à sacra ley ceñido. ${ }^{53}$

En la comparación vuelve a salir victorioso el modelo teresiano, que, si bien no es tan juiciosa como sor Juana, según Don Joseph, es superior por estar atada a la ley sagrada y a la purificación de su alma mística, como si una estuviese atada al cielo, a diferencia de la monja novohispana, apegada al mundo, fuente de perdición vanidosa. La evidencia la vemos en la censura a su modelo poético, fuente de perdición vanidosa y peligrosa para el alma virtuosa:

¿Quién no tendrá peligro en desvanecerse con tan primoroso Numen [la poesía], que alhagase el sentimiento, diese gloria al amor, reglas al plectro, reglas al Arte, y encantos al oído? Solo mi Santa Madre [Santa Teresa] pudo hollar los peligros, porque sin entenderse con el viento, y victoriosa de quanto pudiera surgir vanidad, consagró sus harmonías [versos poéticos] á su dulce y santo amor. Esta fuè la Santa Madre como Poetisa, ¿y habrá alguna tan débil [sor Juana], tan ligera que quiera igualarse á la Seráfica Doctora. Pobrecita! Tenedle mucha lástima". ${ }^{54}$

No suficiente con esta crítica, el arzobispo de Burgos celebra la censura que el obispo de Puebla, Manuel Fernández de la Santa Cruz le hiciera a sor Juana en 1691 a propósito de la respuesta que ella diera en su Carta Atenagórica de 1690, en contra del sermón el Mandato, escrito en 1650 por el teólogo jesuita portugués Vieyra, a lo que Don Joseph añade: "Yo añadiría algo más [a la censura del obispo poblano], y es que no fuesen en tanto número, que se expongan por èl al común desprecio, y à ocupar con tanto exceso la

\footnotetext{
${ }^{52}$ Ibid., 463.

${ }^{53}$ Ibid., 464.

${ }^{54}$ Ibidem.
}

www.enclavesdelpensamiento.mx https://doi.org/10.46530/ecdp.v0i30.408 
memoria, que en la oración, y en el oficio no se logre la quietud, y aún si esté haciendo coplas en la oración". ${ }^{55}$ Es decir, añade el consejo de no dedicarse a producir tantas poesías ni al estudio erudito y dedicarse más a la oración.

Vemos claramente una censura a la "técnica del yo" de la escritura, pues no se quiere producir una subjetividad femenina erudita e identificada con la filosofía y el saber, ese modelo no conviene al poder pastoral masculino, sino aquel que permita la construcción de una subjetividad basada en la vida ascética, ligada a los modelos de sumisión y obediencia de las mujeres, de control de los placeres del cuerpo como la entiende el cristianismo.

Otra de las razones para censurar la escritura secular podría deberse a que la palabra es análoga del cuerpo, en el sentido de su gran poder persuasivo o retórico. Busca producir emociones en los receptores. La palabra funcionaría como el cuerpo de los pensamientos, equivalente a la sensualidad por la producción de los afectos. De alguna forma, la sensualidad de la palabra estaría atada al placer del cuerpo en el oído de los receptores, en la visión por las imágenes evocadas en la fantasía, pero también por satisfacer la vanidad de la escritora.

Si la vanidad va asociada a la producción poética, entonces es razón para censurarla. El promover la renuncia a estos placeres de agudeza e ingenio tiene que ver con la ideología cristiana de la caída por el pecado original, pues justo lo que perdió a la humanidad por la caída de Eva fue un acto de soberbia por la ambición del saber. Don Joseph está asociando a sor Juana con esta actitud intelectual y vanidosa, por su amor al estudio y al saber, inconveniente para la conducta ascética esperada en una religiosa.

Sor Juana Inés de la Cruz fue luz de la sociedad en el sentido de que todos la consultaban, como a un Sócrates; desde virreyes hasta obispos, y no sólo en la Nueva España sino en el mundo transatlántico, de ahí que tanto su confesor Manuel Fernández de la Santa Cruz como Don Joseph, la reprendan con argumentos similares, mientras que a Teresa de Jesús, patrona de su congregación de Carmelitas Descalzas, la alaban.

\footnotetext{
${ }^{55}$ Ibidem.
} 


\section{Conclusiones}

En esta investigación se logró mostrar las prácticas de "tecnologías del yo" en la vida conventual femenina novohispana del siglo XVII, análogo a como lo hizo Foucault en el caso del cristianismo antiguo, haciendo uso de las investigaciones de Muriel, Lavrin y Bieñko para analizar los casos retratados sólo como ejemplos de "tecnologías de interiorización" para lograr un conocimiento de sí mismas a través de su ascetismo. En suma, una práctica de "biopolítica neumática" como los ejercicios de espiritualidad, y junto con las "técnicas de interiorización" mediante la ascética del cuerpo, la sexualidad, los ayunos, la flagelación de la carne y los diarios para el examen de conciencia, la confesión y la obediencia a la dirección espiritual, fueron las diversas maneras como las profesas se produjeron una subjetividad.

Los estudios de las monjas novohispanas del siglo XVII de las investigadoras citadas en este trabajo nos brindaron los ejemplos necesarios para mostrar el ejercicio de “tecnologías de interiorización” — de las que habla Michel Foucault en Tecnologías del yo-, cuyas prácticas conventuales consistían en intentar saber lo qué estaba pasando dentro de sí mismas, admitir las faltas, reconocer las tentaciones, ubicar los deseos, cada una estaba obligada a revelar esto, ya fuese a Dios, a la comunidad y al confesor, como testimonio público este último o bien testimonio privado, dentro de la conciencia personal y de reconocimiento frente a la conciencia de sí; obligaciones de fe y de los votos de la profesa, como fueron la obediencia a la regla de su congregación, lo cual permitiría la purificación del alma que sería imposible de lograr sin un conocimiento de sí misma, de ahí la práctica de la escritura de las religiosas en los claustro con la finalidad de examinar la conciencia, así como para la confesión.

Además, mostramos la política de poder pastoral en torno a la escritura femenina conventual en el siglo XVIII, como otro caso de prácticas de "biopolítica neumática", es decir, del control de la vida de las monjas a través de escritura en los claustros con este sermón religioso de Don Joseph. Nos centramos en su fuerza persuasiva para producir emociones y convencer a la receptora de cambiar su vida. Analizamos el contenido de esas máximas espirituales promovidas por el arzobispo de Burgos como formas de 
producción de la subjetividad femenina virtuosa, en particular en los ejercicios poéticos de dos religiosas, una española del siglo XVI, Santa Teresa de Jesús, y otra novohispana del siglo XVII, sor Juana Inés de la Cruz, y cómo sirvieron para controlar este tipo de prácticas en la "biopolítica neumática" a través del sermón y la retórica; si bien las separaba un tiempo histórico y cultural distinto, el consejero del Rey las utiliza como modelos retóricos para promover la virtud de las Carmelitas Descalzas y persuadirlas del mal uso de los ejercicios poéticos, cuando son producidos por el ingenio y la audacia, porque le parecen vanidosos y distractores de la devoción. Al analizar los consejos del sermón a la luz de las categorías teóricas de Michel Foucault, vemos como esta política pastoral en torno al ejercicio de la escritura de la carmelita descalza del siglo XVIII nos parece una práctica de gubernamentalidad y "tecnología del yo" al promover abnegación, desapego del mundo, represión de los placeres mundanos, preparación para la muerte, y obediencia absoluta.

Sabemos que la comparación poética de estas dos religiosas es inadecuada porque sor Juana no es mística, mientras que Santa Teresa sí lo es, hacerlo obedece a las intenciones del consejero del Rey. No obstante, en los investigadores citados en este trabajo, las analogías que éstos encuentran entre ellas aparecen al revisar sus biografías, en la manera como tuvieron que enfrentarse al control eclesiástico, la persecución de la que fueron objeto y los obstáculos en su camino, pero no comparan ni sus formas ni intenciones poéticas. 


\section{Bibliografía}

Amerlick, María Concepción, y Manuel Ramos. Conventos de monjas: Fundaciones en el México Virreinal. México: Grupo Condumex, 1995.

Bieñko de Peralta, Doris. "Voces del claustro. Dos autobiografías de monjas novohispanas del siglo XVII". Relaciones: Estudios de historia y sociedad, 35, núm. 139 (junio-agosto, 2014). http://www.scielo.org.mx/scielo.php?script=sci_arttext\&pid=S018539292014000300008 .

Foucault, Michel. El Poder: cuatro conferencias. México: Universidad Autónoma Metropolitana, 1989.

Foucault, Michel. Nacimiento de la Biopolítica. México: Siglo XXI Editores, 1990.

Foucault, Michel. Historia de la sexualidad, vol. 2. México: Siglo XXI Editores, 1993.

Foucault, Michel. Obras esenciales. Barcelona: Paidós, 1999.

Gonzalbo, Pilar. Las mujeres en la Nueva España, educación y vida cotidiana. México: El Colegio de México, 1987.

Hamui, Silvia. "Aspectos sobre la escritura mística”. En Jessica Ramírez y Mario C. Sarmiento Zúñiga (coord.), La presencia de la orden del Carmen Descalzo en la Nueva España. Interacciones, transformaciones y permanencias, México: Instituto Nacional de Antropología e Historia, 2019.

Jáuregy, Carlos A., y David Solodkow. "Biopolitics and the Farming (of) Life Bartolomé de Las Casas”. En David Thomas Orique, O. P. y Rady Roldán-Figueroa (eds.), Bartolomé de las Casas, O. P. History, Philosophy and Theology in the Age of European Expansion. Ed. Leiden-Boston: Brill, 2019.

Lavrin, Asunción. Las esposas de Cristo: La vida conventual en la Nueva España. México: Fondo de Cultura Económica, 2016.

Martínez Cabrera, Erika. “Sor Juana y Santa Teresa: dos ventanas una luz”. Ponencia II Congreso Internacional CELEHIS de Literatura. Argentina: Universidad Nacional del Mar de la Plata, Facultad de Humanidades, Centro de Lenguas Hispanoamericanas, 2004. 
Mayer, Alicia. Lutero en el Paraíso. La Nueva España en el espejo del reformador alemán. México: Instituto de Investigaciones Históricas, UNAM / Fondo de Cultura Económica, 2008.

Montero, Alma. Monjas Coronadas: Profesión y muerte en Hispanoamérica virreinal. México: Museo Nacional del Virreinato-Plaza y Valdés Editores, 2008.

Muriel, Josefina. Cultura femenina novohispana. México: Universidad Nacional Autónoma de México, 1982.

Ramírez Méndez, Jessica, y Mario C. Sarmiento Zúñiga (coords.), La presencia de la Orden del Carmen Descalzo en la Nueva España. Interacciones, transformaciones e itinerancias. México: Instituto Nacional de Antropología e Historia, 2019.

Ríos Espinosa, María Cristina. "Biopolíticas colonialistas en las Nahuas de la Nueva España en el siglo XVI”. Revista Reflexiones Marginales, núm. 9 (junio, 2020). https://revista.reflexionesmarginales.com/biopoliticas-colonialistas-en-las-nahuasde-la-nueva-espana-en-el-siglo-xvi/.

Rodríguez de Arellano, Joseph Xavier. Avisos espirituales que dió a sus hijas la seráfica doctora Santa Teresa de Jesús, y explica en pláticas su devoto el ilustrísimo señor Don Joseph Javier Rodríguez de Arellano, Arzobispo de Burgos, del Consejo de su Majestad y dedica a las venerables preladas y religiosas de los monasterios de su filiación, vol. 2. Burgos: Joseph de Navas, 1780. Archivo Histórico Nacional. Inquisición. 1731. Exp. 34.

Rodríguez, Adriana, y Fernando Ciaramitaro. “Alumbradas e ilusas de Nueva España. Un estudio a través de la documentación del Santo Oficio”. Revista de Inquisición. Intolerancia y Derechos Humanos 20 (2016): 109-130.

Rubial, Antonio. El paraíso de los elegidos: Una lectura de la historia cultural de Nueva España (1521-1804). México: UNAM / Fondo de Cultura Económica, 2010.

Rubial, Antonio. Monjas, cortesanos y plebeyos: la vida cotidiana en época de Sor Juana. México: Taurus, 2012. 
Wissmer, Jean-Michel. "Santa Teresa y Sor Juana: diálogo entre dos hermanas”. Revista La Colmena, no. 47 (julio-septiembre, 2005). http://web.uaemex.mx/plin/colmena/Colmena\%2047/Aguijon/Jean.html.

Zayas, Concepción. Ana de Zayas: escritora y maestra del espíritu. Heterodoxia y neoplatonismo en una seglar de la Puebla de los Ángeles (siglo XVII). México: Benemérita Universidad Autónoma de Puebla, 2017. 